\title{
Probe on the use of plastic pyrolysis oil as substitute fuel in a CRDi engine with metal based (titanium oxide) nano additives
}

\author{
M.Venkata subbaiah ${ }^{1}$, S.Sunil kumar reddy ${ }^{2}$ B.Durga prasad ${ }^{3}$ \\ ${ }^{* 1}$ Ph.D Research Scholar, Department of Mechanical Engineering, Jawaharlal Nehru Technological University, \\ Anantapur, Ananthapuramu. \\ ${ }^{2}$ Professor and Head of Mechanical Engineering, Siddharth Institute of Engineering \& Technology, Puttur, \\ ${ }^{3}$ Professor\& COE, Department of Mechanical Engineering, JNTUA Ananthapuramu
}

\begin{abstract}
In the previous part we were told that plastic oil 20\% blend was optimum. This paper presents the three nano additives which are Metal Based, Oxygenated and Organic Additives which we have selected as Metal-Based as Titanium Oxide nano additive because of that plastic Oil viscosity Decreases as well as increases flowbility,and reduce the emissions. We have some techniques to reduce Pollutions that are EGR, Exhausted After Treatment and Compression Ratios All are Old techniques. The New Technique is Adding Nano Additives with plastic oil.Tio 2 nanoparticles are sprinkle in the emulsions with various dosage intensity of 25, 50, 75, and 100ppm. A single-cylinder, four-stroke CRDI diesel engine is made to run on different fuel engrossment to swotting the end result of emission hallmark of the fuel. The test engine was exercise under constant engine speed (1500 rpm) and different engine load test conditions. According to the experimental results, fuel blends with biodiesel fuel emission aggravate NOx and diminish the $\mathrm{CO}, \mathrm{HC}$, and smoke emissions contrast with the wpo20 fuel. The experimental result shows heat release rate and cylinder peak pressure obtained was of $15.38 \%$ and $40 \%$ for WPO20+50ppm tion. And also observed that WPO 20+50ppm tio2 has $5.72 \%$ higher brake thermal efficiency was found as compared to wpo20\% at full load. On the other hand 100ppm tio2 blend also resulted increase NOx emission by $25 \%$, smoke opacity decreases by $46 \%$ as well as higher for full load. But UHC and CO emissions are slightly decreased with compared the wpo20 fuel.
\end{abstract}

Keywords: CRDi engine; combustion; injection timing; Tio2 nano additive : emissions; performance EGR.

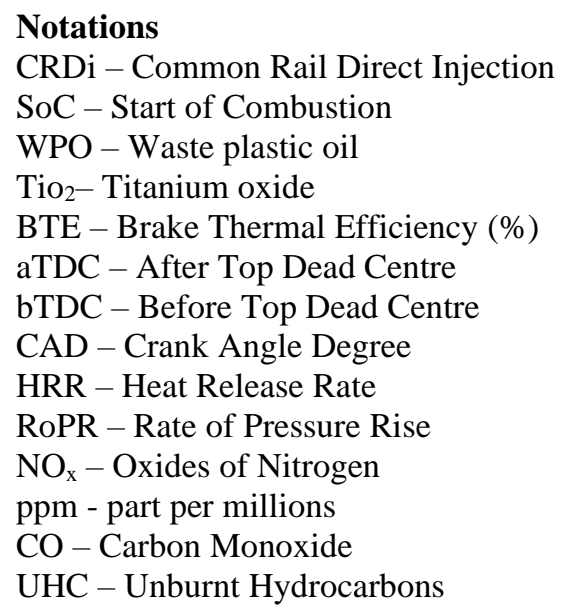

\section{INTRODUCTION}

The main goals of today's automobiles are to enhance fuel economy and lower pollution. To resolve the above aims, many researchers are concentrating on the CRDi engine. In a single-cylinder diesel engine, he conducted experiments with titanium oxide nanoparticles and water-in-diesel. The results were attained at full load condition brake thermal efficiency increases and emissions are decreases omitting Oxides of nitrogen. It was recognized that $\mathrm{TiO} 2$ fused emulsion fuel (DWT) could be a promising alternative fuel for a diesel engine without the need for hardware changes in the near future. R. Vigneswaran et al[1] He has carried out the corn oil biodiesel with Lanthanum oxide (La2O3) was used as an additive with neat diesel fuel and blends were prepared and performed experiment on A single-cylinder, four-stroke CRDI diesel engine on different fuel according to the experimental results, fuel blends with biodiesel fuel 


\section{DOI: 10.17148/IARJSET.2021.8827}

emission increasesCO2 and $\mathrm{NOx}$ and reduces the $\mathrm{CO}, \mathrm{HC}$, and smoke emissions compared with the B20 fuel. S. Karthikeyan et al [2] In a twin-cylinder water-cooled direct-injection four-stroke diesel engine, he evaluated the effect of zinc oxide and titanium dioxide nanoparticles added in Calophyllum inophyllum biodiesel (CIME). Due to the increased surface to volume ratio of nanoparticles, diesel engine running with CIME nanoemulsions enhances brake thermal efficiency when compared to pure CIME fuel at maximum braking power. Nanthagopal et al[3] Using Calophyllum Inophyllum biodiesel blends with $\mathrm{TiO} 2$ nano additions and exhaust gas recirculation, an experimental examination was carried out to evaluate the performance and emission characteristics of a single-cylinder diesel engine (EGR) In comparison to the B20 fuel, NOx emissions were reduced with the EGR approach and increased with the addition of $\mathrm{TiO} 2$ nanoparticles to the biodiesel blend.. Praveen A et al[4] This review shed light on the use of nanoparticles (as a nanocatalyst) in compression ignition engines, owing to its potential to improve the thermo physical properties such as the high surface area to volume ratio, thermal conductivity, and mass diffusivity when dispersed in any base fluid medium Information indicates that addition of nanoparticles(such as cerium oxide, aluminium, alumina, and carbon nanotubes) to any conventional fuel (such as diesel) enhances the combustion efficiency, reduces harmful pollutants, enhances ignition temperature improved specific fuel consumption, favors reduced evaporation time, and leads to shortening ignition delay owing to their better combustion characteristics.Basha.J.et al[5] He discovered that blending aluminium oxide nanoparticles into fuel reduces specific fuel consumption and exhaust pollutants significantly at all running loads. The magnitude of $\mathrm{HC}$ and smoke emission for the ZJME25 before the addition of aluminium oxide nanoparticles was $13.459 \mathrm{~g} / \mathrm{kW}$ h and $79 \mathrm{HSU}$ at full load, whereas the AONP 50 blended ZJME25 was $8.599 \mathrm{~g} / \mathrm{kW} \mathrm{h}$ and $49 \mathrm{HSU}$ at full load. .C. Syed Aalam et al[6] He was shown the decrease in smoke levels with that of benchmark squander plastic pyrolysis oil. The BTE (brake warm proficiency) expanded when contrasted with unadulterated plastic pyrolysis oil and diesel. The toxins like CO (carbon monoxide) and NOx (nitrous oxide) were decreased in the mix. It was seen that expansion of oxygenates had further developed the ignition interaction and diminished the outflows.

The examination uncovered that mixing of DEE with plastic oil expands the Cetane rating which is better than perfect diesel. J. Devaraj et al [7] It was inferred that the expansion of metal-based ( $\mathrm{Mn}, \mathrm{Ni}, \mathrm{Mg}, \mathrm{Co}$ ) added substances and scarcely any oxygenated added substances to the biodiesel mix decline the thickness, thickness, and glimmer point, however, the oxygen content of the mix is expanded and metallic and CNTs nano-added substances were found good as for their consequences for outflow decrease and motor execution improvement. $\mathrm{TiO} 2$ added substances were more compelling in upgrading the motor force. The expansion of metallic NPs brought about a diminished start defer period upgraded the calorific worth and oxidation rates prompting a total and cleaner ignition. Manzoore Elahi M. Soudagara et al[8] He was investigated on diesel engine emissions characteristics under various engine process parameters such as Jamun Seed oil, injection pressure ,brake power and $\mathrm{TiO} 2$ were teste. He found that the emissions are less than that for diesel Significant diesel displacement is achieved at all BP, Reasonable reductions in NOx was demonstrated but considerably higher $\mathrm{CO}$ and $\mathrm{HC}$ emissions results from fuel operations especially at low loads. It is observed that HC emission is formed where the mixture ratio is lean at low loads B.R. Ramesh Bapu et al[9] He led investigations the dosing amount of $\mathrm{Al} 2 \mathrm{O} 3$ and $\mathrm{Fe} 3 \mathrm{O} 4$ nanoparticles differ from 40 to 120 ppm into the MME20 fuel mix with the help of an ultrasonicator. The results acquired from this investigation demonstrated that the MME20 diminishes the CRDI diesel motor brake warm effectiveness and expands its emanation. The gathering of $\mathrm{Al} 2 \mathrm{O} 3$ and Fe3O4 nanoparticles was begun to upgrade the brake warm effectiveness and ignition boundaries. The best outflow qualities are gotten at a dosing of $80 \mathrm{ppm}$ of $\mathrm{Al} 2 \mathrm{O} 3$ and $\mathrm{Fe} 3 \mathrm{O} 4$ nanoparticles. Essentially better burning qualities are seen at a dosing of 80 ppm of $\mathrm{Al} 2 \mathrm{O} 3$ contrasted and $\mathrm{Fe} 3 \mathrm{O} 4$ nanoparticles.C. Syed Aalam et al[10] He directed investigations on Titanium dioxide nanoparticles that are utilized as a fuel added substance in a packed start motor and execution, outflow tests for diesel fuel and diesel fuel with $\mathrm{TiO} 2$ nanoparticles were performed. It is seen that with the expansion of nanoparticles there is an increment in brake warm productivity of the motor. Brake-explicit fuel utilization diminishes by $22 \%$ at greatest burden with the expansion of $\mathrm{TiO} 2$ nanoparticles. Among emanations, the expansion of $\mathrm{TiO} 2$ nanoparticles diminishes discharges of unburnt hydrocarbons by $18 \%$ and carbon monoxide by $25 \%$. Rolvin D'Silva et al[11] He exploration on the impacts of blends of waste cooking oil methyl ester and various metal-oxide-based nanoparticles on the emission, combustion, performance, vibration, and noise characteristics of a single-cylinder diesel engine, and examined various fuels were tested.

The addition of metal-oxide-based nanoparticles has firstly increased the viscosity, cetane number, and heating value of biodiesel. Higher oxygen atoms in biodiesel-nanoparticles blends have improved the quality of the combustion process.CO, HC, and NOx emissions were significantly reduced with the blending of nanoparticles and biodiesel in comparison with those of D100. The addition of nanoparticles highly improved engine performance. In conclusion, this study is suggesting that the addition of metal-oxide-based nanoparticles into biodiesel blends can give better results than using biodiesel alone for diesel engine. Ümit Ağbulut et al[12] The target of this venture is to examine the potential impacts of adding nanoparticles with diesel. The venture is imagined subsequent to understanding the genuine need to work on the effectiveness of the diesel motor without impacting the discharges to an extreme degree. The nanoparticles are utilizing for the task are Zinc Oxide and Copper oxide, this undertaking includes two separate tests on 


\section{DOI: $10.17148 /$ IARJSET.2021.8827}

a similar structure of these nanoparticles with the upsides of diesel utilized as a kind of perspective. In the current work, test examinations have been done on utilizing $\mathrm{ZnO}$ nanoparticles with diesel. The current work predominantly centers around contrasting the diverse nanoparticles with diesel with work on the presentation of pressure start motors. In stage we take another nanoparticle was to take to examine to work on the presentation of DI Diesel motors.. A.Selvaganapthy et al [13] This trial examination plans to consider the exhibition, burning, and emanation attributes of normal rail direct infusion (CRDI) fuelled with squander plastic oil and diesel mixes at various infusion methodologies and at different stacking conditions. From the outcomes, it is seen that slight decrease in the warm productivity of the motor when worked with squander plastic oil $(100 \%)$ because of high consistency and lower warming worth. There was a groundbreaking diminishment in NOx discharges for low infusion pressing factors of plastic diesel mix (P30). This examination shows that squander plastic oil mix can be effectively utilized as fuel in diesel engine with no impressive changes Arani Vijay Rao Krishna Chaitanya et al[14] He has conducted the experiments on CRDI diesel engine with WPO oil by recalculating by exhaust gases and observed that $36.3 \%$ of maximum NOx reduction was achieved with the help of $20 \%$ EGR rate. Archit s. adyodhya et al[15] This study shows that with the usage of low viscous oil, the transesterification process is eliminated and the Nano additive helps in the improvement of the combustion process. Emulsion helps in the reduction of NOx emission. Hence, this blend can be effectively used to reduce the dependency on the fossil fuel as well as to reduce the harmful emissions. Mebin Samuel Panithasan et al[16] He investigation on the addition of aluminium oxide Nano particles along with the emulsified fuel blend and records the reduction of emissions and increase in efficiency. Pradeep, P t al [17] He investigated the emulsion of Borassus-flabellifer oil along with an oxygenate additive of 1,4-dioxane to reduce NOx emission and to improve the combustion and efficiency of the fuel. Ramalingam, K et al[18] He examine on optimal blend was ultrasonicated with nano titanium oxide (0-100ppm). The addition of titanium oxidenano into biodiesel butanol blends was attractive and it improved the essential properties. Results of the property testing showed that $35 \%$ butanol can be blended with biodiesel to obtain blend possessing similar properties in comparison to that of diesel. In-cylinder peak pressure and thermal efficiency produced by the biodiesel butanol blend containing 50ppm of nano titanium oxide were found higher in comparison to that of diesel. Emissions of oxides of nitrogen, smoke, carbon monoxide and hydrocarbon produced by this blend were also found significantly lower compared to that of diesel. This was due to the inclusion of nano titanium oxide into the blend. Prabakaran, B et al[19]Previous researcher work gap identified there is no work is done on WPO with tio2 nano additive in CRDi. So in this investigation to study the combustion performance and emission characteristics on CRDi single cylinder diesel engine by using WPO $20,25 \mathrm{ppm}$ tio2,50ppm tio2,75ppm tio2, and 100ppm tio2 nano additive biodiesel blends presented in this paper.

\section{METHODS AND MATERIALS:}

It has performed an experiment for detecting the properties of the pyrolysis oil The process involves washing of waste for several time to ensure dust elimination. After which the waste is dried up to room temperature to remove moisture content. The plastic is heated at 270-430 K. As a result of this pyrolysis, three products are obtained Pyrolysis Oil (60$70 \%)$, Gas (15-20\%) and plastic waste (20-30\%). Further the mixture of blends containing, 5\% oil+ $95 \%$ diesel, $10 \%$ oil $+90 \%$ diesel, $15 \%$ oil $+85 \%$ diesel, $20 \%$ oil $+80 \%$ diesel are subjected to various characteristic tests and are found similar to that of pure diesel oils.

\subsection{FEEDING INTO REACTOR:-}

After completion of cutting and drying process the plastics are allowed to feed into the reactor. Before feeding into the reactor we should weigh the input plastics just as to check how much amount of fuel we may get from it.

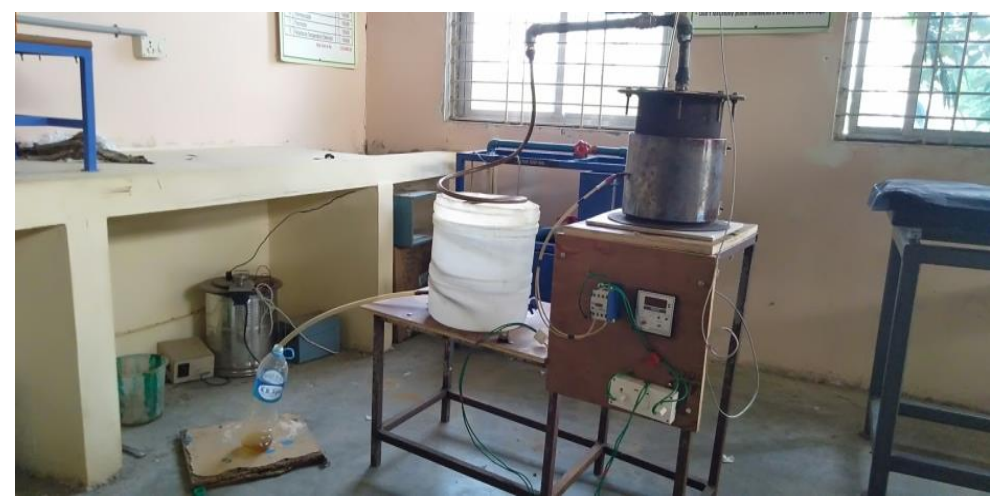

Fig.2. pyrolysis machine 


\title{
International Advanced Research Journal in Science, Engineering and Technology
}

\author{
Vol. 8, Issue 8, August 2021
}

DOI: $10.17148 /$ IARJSET.2021.8827

\subsection{MOVEMENT OF LIQUID-VAPOUR INTO CONDENSER:}

The vapours that escape from the reactor enter the condenser through pipelines. Water comes into touch with the spiral copper tube that makes up the condenser pipe. The vapours that enter the condenser pipe begin to cool and exchange heat with the copper pipes, which is detected by the water in the chamber. As a result, vapours cool down to become liquids at normal temperature.
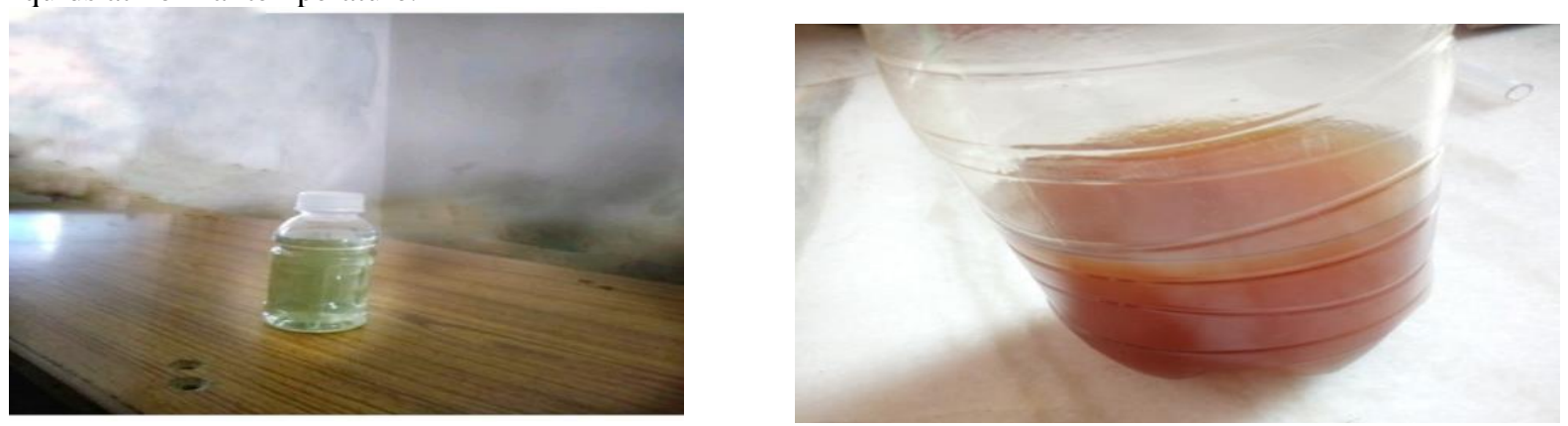

Fig.3. Plastic fuel collected

We got the liquid fuel in the crude form. When we burnt the pyrolysed oil we noticed that some amount of oil doesn't burn and is left residue along with burning fuel. To make it burnt efficiently we moved to refine the obtained oil. After the completion of the process we noticed that some amount of dark black viscous semisolid inside the reactor. This is called "asphalt" or "bitumen". This is residue in crude oil distillation.

Table.1. properties of waste plastic oil and diesel

\begin{tabular}{|l|l|l|l|l|l|l|}
\hline Type of fuel & Density $(\mathrm{kg} / \mathrm{m} 3)$ & $\begin{array}{l}\text { Calorific value } \\
(\mathrm{kJ} / \mathrm{kg})\end{array}$ & $\begin{array}{l}\text { Kinematic } \\
\text { viscosity } \\
@ 40{ }^{\circ} \mathrm{C}\end{array}$ & $(\mathrm{Cst})$ & Cetane number & $\begin{array}{l}\text { Flash } \\
\text { Point }\left({ }^{\circ} \mathrm{C}\right)\end{array}$ \\
\hline WPO20 & 864 & 38000 & 4.71 & 46 & 96 \\
\hline WPO20+25PPM & 868 & 38150 & 4.77 & 48 & 121 \\
\hline WPO20+50PPM & 876 & 38270 & 4.79 & 54 & 126 \\
\hline WPO20+75PPM & 878 & 38530 & 4.74 & 56 & 128 \\
\hline WPO20+100PPM & 867 & 38700 & 4.43 & 53 & 132 \\
\hline
\end{tabular}

\section{Characterization of $\mathrm{T}_{\mathrm{i}} \mathrm{O}_{2}$ Nanoparticle \\ XRD report}

The XRD denotes X-ray diffraction. This type of study would be more fruitful in finding out non-destructive and crystallographic structure, chemical composition and physical proper- ties of engineering materials. In order to test the extent to which the distribution of $\mathrm{TiO}_{2}$ nanoparticles has taken place, and to get unit cell dimensions of the areas where more concentration of the base matrix and reinforcement takes place. It can also be used to measure various structural properties of these crystalline phases such as strain, grain size, phase com- position and defective structure. XRD pattern of $\mathrm{T}_{\mathrm{i}} \mathrm{O}_{2}$ nanoparticle is shown in Fig. 2(a). XRD pattern shows the main reflections at peaks as characteristic of $\mathrm{T}_{\mathrm{i}} \mathrm{O}_{2}$ nanoparticles. All the peaks in XRD pattern show the anatase phase of $\mathrm{T}_{\mathrm{i}} \mathrm{O}_{2}$ nanoparticles. The size of the nanoparticle ranges from 30 to $40 \mathrm{~nm}$. In this study, it is observed that the XRD profile con- tains four sharp well-defined intense peaks. The peaks are related to $\mathrm{TiO}_{2}$.

\section{SEM image report}

Scanning electron microscopy (SEM) can be used to investi- gate the nanoparticle of $\mathrm{TiO}_{2}$ composite. Surface and morphology of nanoparticles were carried out by using scanning electron microscopy. Figure 2(b) shows the FESEM images of $\mathrm{TiO}_{2}$ nanoparticle. Microstructure of $\mathrm{TiO}_{2}$ revealed good met- allurgical bonding among the particles. Dark black regions are present. They can be observed within boundaries (i.e. at the area of boundary region). The images were recorded at $10 \mu \mathrm{m}$. The photographic view shows clearly the visible crystallite present in the powder material, which is highly agglomerated. The bright spots exhibit the high crystalline nature of the ma- terial in the selected area electron diffraction. The particle size observed from SEM was in the range of 30 to $40 \mathrm{~nm}$. SEM image of $\mathrm{T}_{\mathrm{i}} \mathrm{O}_{2}$ nanoparticles is shown in fig 2 (b) 
Vol. 8, Issue 8, August 2021

DOI: $10.17148 /$ IARJSET.2021.8827
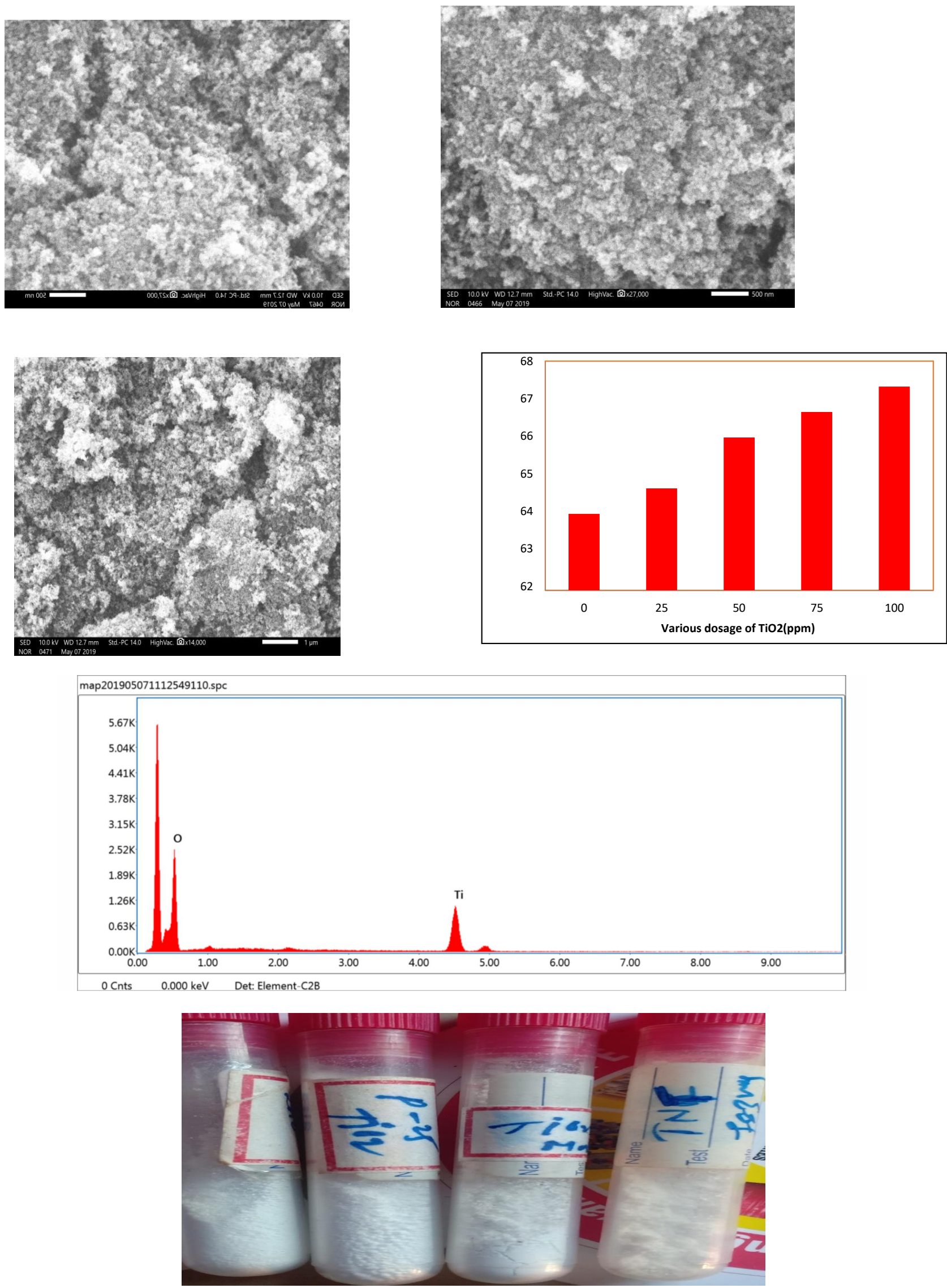

Fig.4. Different proportions of $\mathrm{TiO}_{2}$ nano additives 


\title{
International Advanced Research Journal in Science, Engineering and Technology
}

\author{
Vol. 8, Issue 8, August 2021
}

\section{DOI: 10.17148/IARJSET.2021.8827}

\section{EXPERIMENTAL SETUP CRDI ENGINE AND EXPERIMENTAL DETAILS}

All the experiments were conducted on the premises of Apex Innovations Pvt. Ltd., Sangli (MS), and India. A single cylinder, naturally aspirated, water cooled, VCR diesel engine coupled with eddy current dynamometer and data acquisition system was used for this investigation. The engine was downsized to develop a maximum power of $3.5 \mathrm{~kW}$ by modifying the engine head by specially designed tilting cylinder block arrangement. The set-up was equipped with a jerk type fuel injection pump and a three hole injector. Initial tests were conducted on this set-up to obtain the reference data The cylinder head was then modified to incorporate a six-hole injector nozzle without altering the combustion chamber geometry to investigate the effects of various FIPs and SITs on engine performance, emission and combustion parameters. The schematic diagram of the test facility is shown in fig. 1. The engine was equipped with a CRDi system (Bosch, E099GF231) to control FIP and SIT. This CRDi engine works with programmable Open ECU (Nira i7r, Sweden) for diesel injection; the engine is equipped with fuel injector, common rail with rail pressure sensor and pressure regulating valve, crank and cam position sensors, fuel pump and wiring harness. The technical specifications of the modified test engine and sensors used for this study are given in Table 1. The test facility was equipped with essential instruments for online measurement of CP, FIP, crank angle, load on the engine, and temperature of -inlet air and exhaust gas, -coolant at inlet and outlet, -lubricating oil. Provision was also made to measure the flow rate of cooling water, -air and -fuel. The entire signaling system was interfaced to laptop through data acquisition system to record all observation parameters using Windows based engine performance software "ICEngineSoft". This software serves the purposes like monitoring, reporting, data entry, data logging. Necessary signals are scanned and stored through online testing of the engine in RUN mode which can be used for further analysis. By providing the input values of density, heating value of fuel and the ambient temperature of air, the software gives the complete summary of combustion and performance of the engine. The exhaust gases were diverted to a sampling line for the measurement of emissions without increasing the back pressure in the exhaust pipe. Five gas emission analyzer (AVL DIGAS 444) and a smoke meter (AVL 437C) were used to measure vital emissions from the engine.

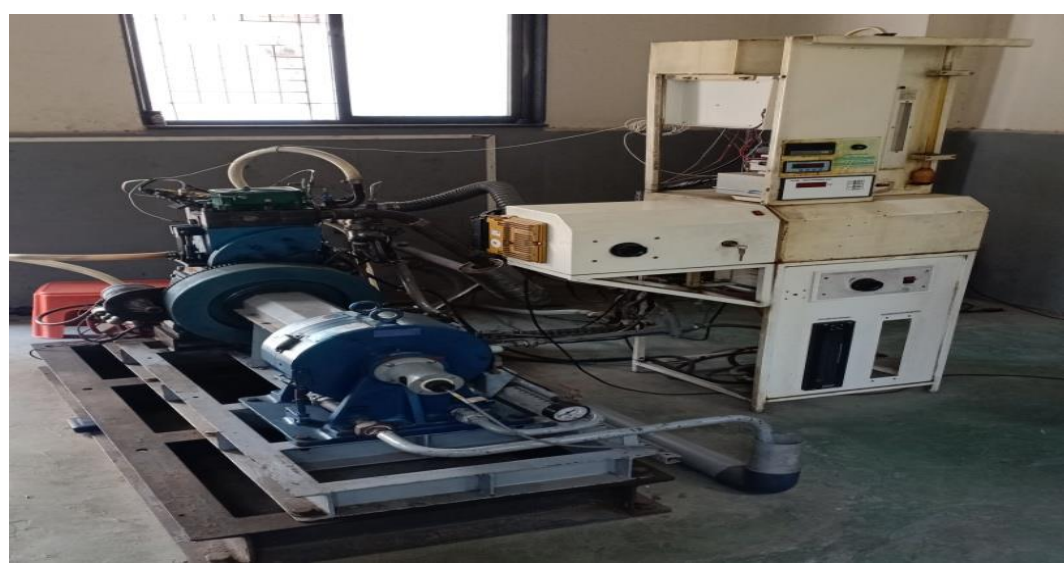

Fig; 4 Photographical View of the experimental setup

\subsection{Dynamometer}

The engine has a DC electrical dynamometer to measure its output. The dynamometer is calibrated statistically before use. The dynamometer is reversible i.e., it works as monitoring as well as an absorbing device. Load is controlled by changing the field current. Eddy-Current Dynamometer's theory is based on Eddy-Current (Fleming's right hand law). The construction of eddy-current dynamometer has a notched disc (rotor) which is driven by a prime mover (such as engine, etc.) and magnetic poles (stators) are located outside with a gap. The coil which excites the magnetic pole is wound in circumferential direction. When current runs through exciting coil, a magnetic flux loop is formed around the exciting coil through stators and a rotor. The rotation of rotor produces density difference, and then eddy current goes to stator. The electromagnetic force is applied opposite to the rotational direction by the product of this eddy-current.

\subsection{Five Gas Analyzer}

All emissions like Carbon monoxide, Carbon dioxide, Un-Burnt Hydrocarbons, Nitrogen oxide and unused oxygen are found in Indus 5 gas emission analyzer of model "AVL DIGAS 444" is used. In this cable one end is connected to the inlet of the analyzer and the other end is connected at the end of the exhaust gas outlet. Continuous charging of the analyzer is essential to work in an effective way. Fig show the actual photos of Exhaust Gas Analyzer attached to engine at the exit. 
Vol. 8, Issue 8, August 2021

DOI: $10.17148 /$ IARJSET.2021.8827

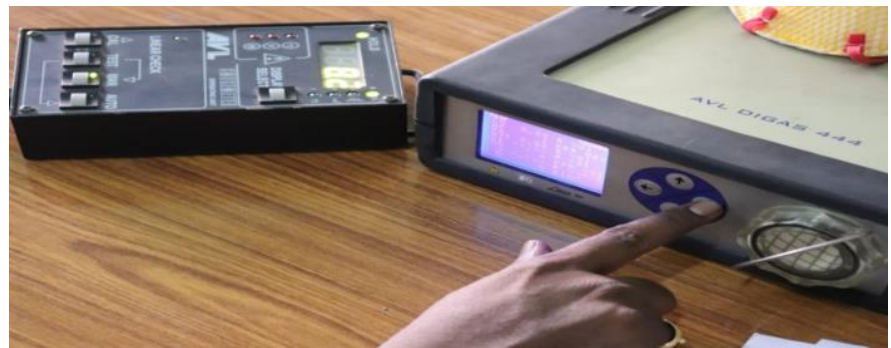

Fig.5. Five Gas Analyzer

Table.2. Experimental engine specifications

\begin{tabular}{|c|c|}
\hline \multicolumn{2}{|c|}{ Engine specification: } \\
\hline Type & 4-stroke, single cylinder diesel engine. \\
\hline Make & kirloskar AV-1 \\
\hline Rated power & $7 \mathrm{KW}, 1500 \mathrm{RPM}$ \\
\hline Bore and stroke length & $85 \mathrm{~mm} \times 110 \mathrm{~mm}$ \\
\hline Compression ratio & 16.5:1. \\
\hline Dynamometer & Rope brake dynamometer. \\
\hline Diameter of brake drum & $0.36 \mathrm{~m}$ \\
\hline
\end{tabular}

\subsection{Combustion parameters}

\section{RESULT AND DISCUSSION}

\subsubsection{Cylinder pressure}

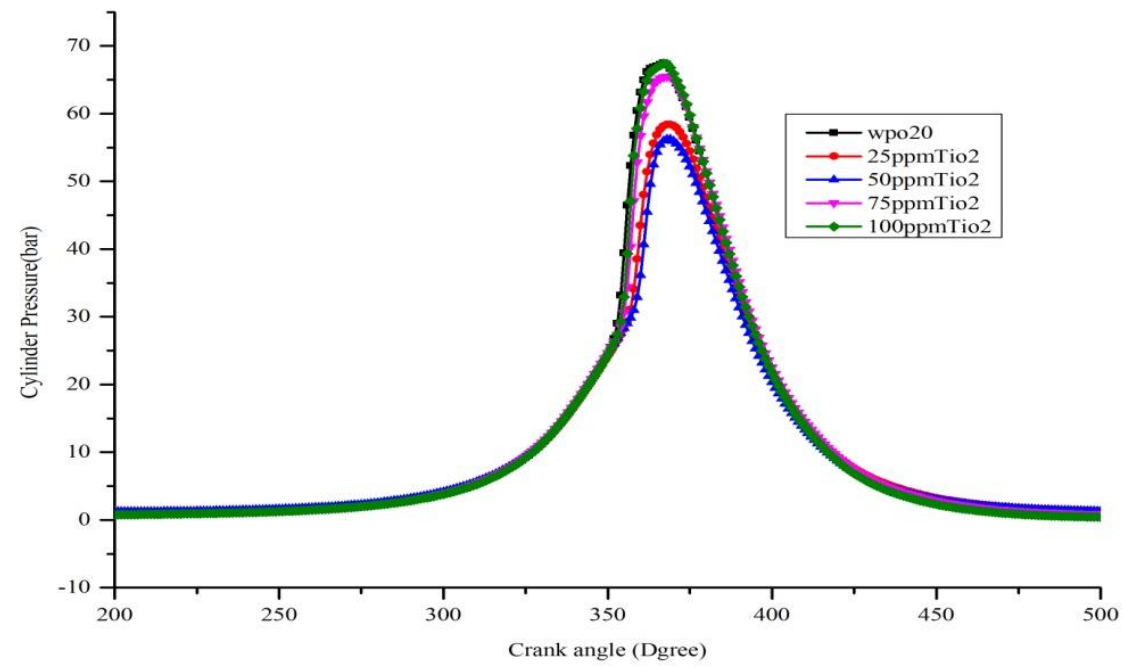

Figure 6.variation of cylinder pressure with crank angle

Figure.6. shows the variation of Cylinder Pressure with respect to Crank angle for the Waste Plastic Oil (WPO) biodiesel blend and compared with the WPO+50ppm tio2. The cylinder peak pressure values for the tested fuels at full load of WPO20 and 25ppm,50ppm, 75ppm and 100ppm is 65 bar, 57 bars, respectively. From the figure it can be noticed that the Cylinder peak Pressure for Waste Plastic Oil (WPO+50ppm) is $15.38 \%$ higher than the WPO20. This can attributed to the higher viscosity possessed by WPO+50ppm, which resulted in low rate of atomization and oxidation in the pre combustion phase. This led to low in cylinder peak pressure and low conversion rate of the thermal energy released during the combustion in the cylinder. 


\section{International Advanced Research Journal in Science, Engineering and Technology}

Vol. 8, Issue 8, August 2021

DOI: 10.17148/IARJSET.2021.8827

\subsubsection{Heat release rate}

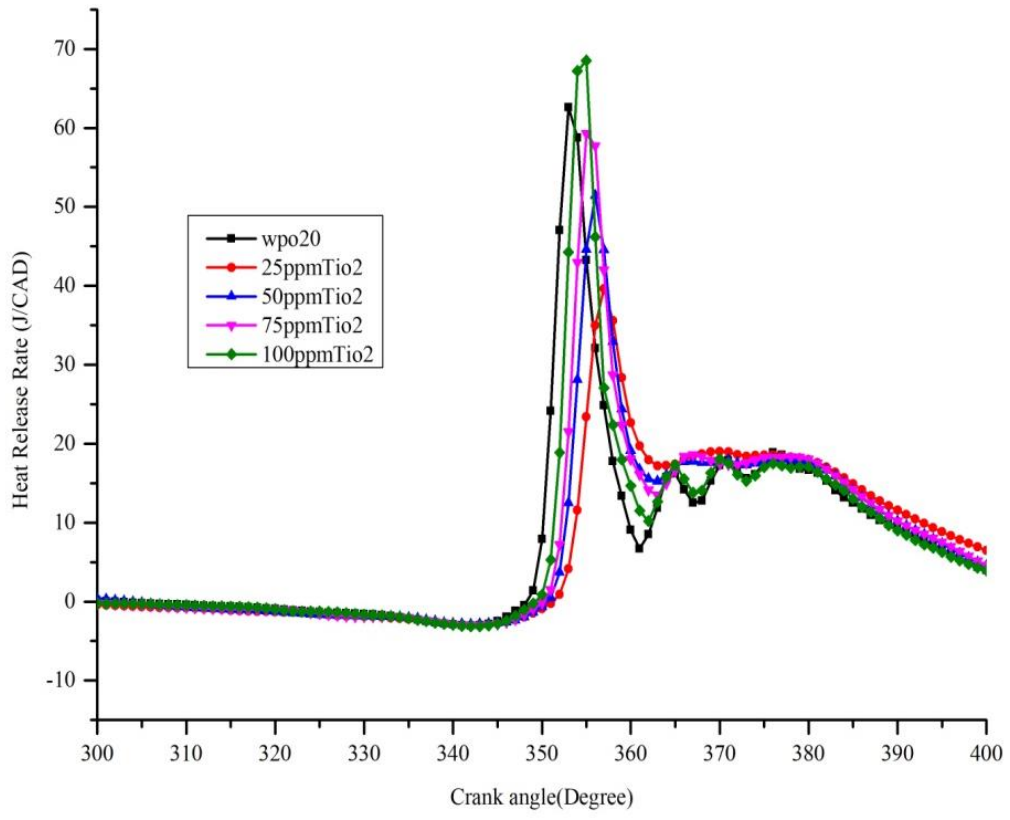

Figure 7. Variation of heat release rate with crank angle

Figure.7 shows the alteration of Heat Release rate w.r.t Crank angle for the WPO 20 biodiesel blend and compared with the WPO20+25ppm. The heat release rate values for the tested fuels at full load of WPO20 and 25ppm,50ppm, 75ppm and $100 \mathrm{ppm}$ is $44 \mathrm{~J} / \mathrm{CAD}$ and $70 \mathrm{~J} / \mathrm{CAD}$ respectively. From the figure it can be stated that the Heat Rease rate for Waste Plastic Oil (WPO+25ppm) is $37.14 \%$ higher than the WPO20. Since longer ignition delays occurs during the pre-combustion period when heat is emitted. The higher heat release rate suggests an improvement in EGT. The twostage ignition decreases with an improved biodiesel content in the test fuels, as demonstrated by heat release curves for all control fuels. It is the calculation of the non-evaporated fuel droplets during SoC production. The high boiling distance of biodiesel contributes to a reduction in dissipation rate. The addition of nano titanium oxide increased the rate of atomization of the fuel blend and increased the HRR to a greater extent.

\section{Rate of pressure rate}

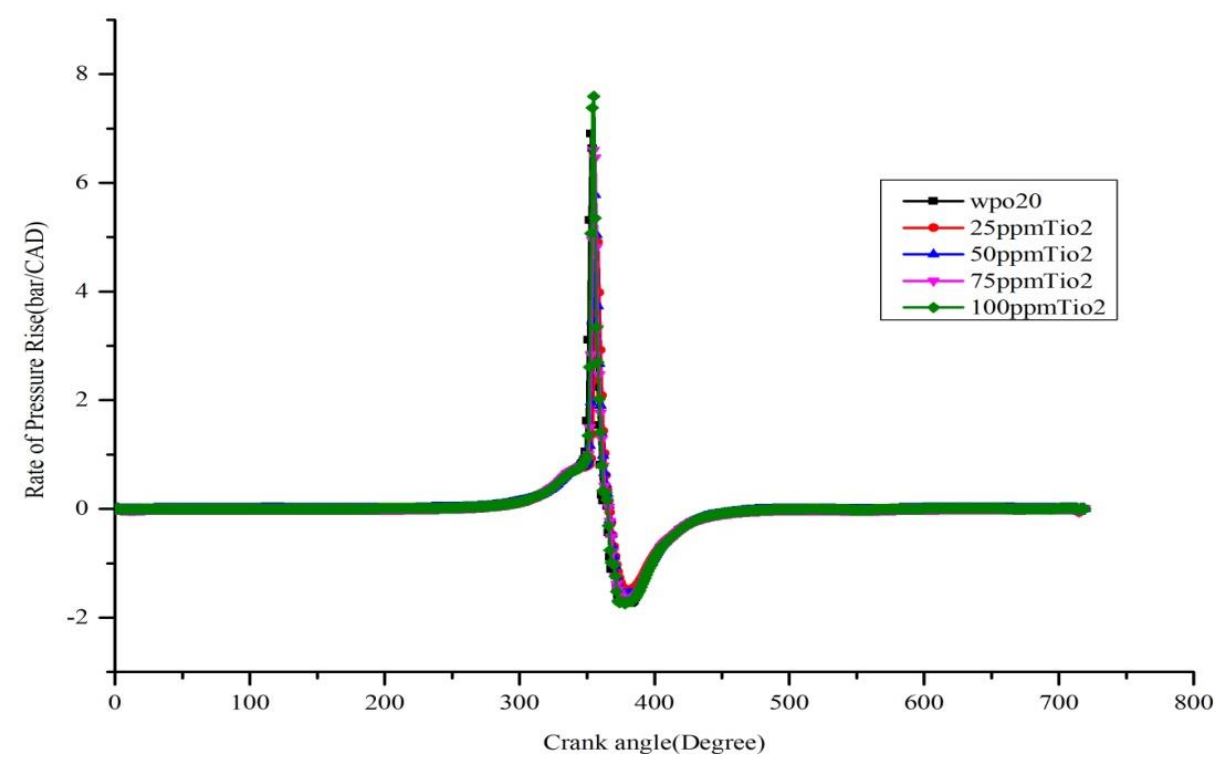

Figure 8. Variation of rate of pressure rise with crank angle

Figure. 8 shows the alteration of rate of pressure rise w.r.t Crank angle for the $25 \mathrm{ppm}, 50 \mathrm{ppm}, 75 \mathrm{ppm}$ and $100 \mathrm{ppm}$ nano additives biodiesel blend and compared with the WPO20. The heat release rate values for the tested fuels at full load of diesel and 25ppm, 50ppm, 75ppm and 100ppm is $4 \mathrm{bar} / \mathrm{CAD}$ and $7 \mathrm{~J} / \mathrm{CAD}$ respectively. From the figure it can be stated 


\section{International Advanced Research Journal in Science, Engineering and Technology}

Vol. 8, Issue 8, August 2021

DOI: 10.17148/IARJSET.2021.8827

that the rate of pressure rise for Waste Plastic Pyrolysis Oil nano additives (WPO+50ppm) is $50 \%$ higher than the diesel. Since longer ignition delays occurs during the pre-combustion period when heat is emitted. The higher heat release rate suggests an improvement in EGT. The two-stage ignition decreases with an improved biodiesel content in the test fuels, as demonstrated by heat release curves for all control fuels. It is the calculation of the non-evaporated fuel droplets during SoC production. The high boiling distance of biodiesel nano additives contributes to a reduction in dissipation rate.

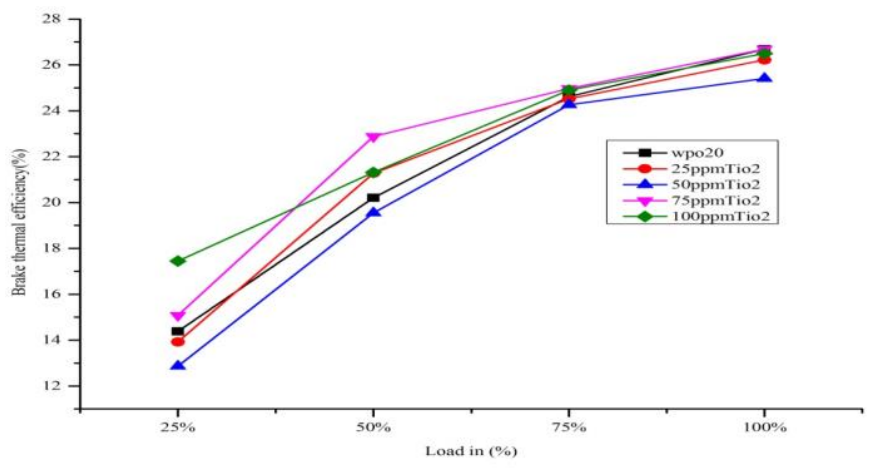

Fig.9. load vs brake thermal efficiency

Figure. 9 shows the brake thermal efficiency figure shows the difference of the brake thermal efficiency for the different wpo with nano additives wpo20, wpo20+25ppm, wpo20+50ppm, wpo20+75ppm and wpo20+100ppm with different load conditions in CRDi diesel engine. The increasing the load conditions increase the brake thermal efficiency also. At the wpo20, 25ppm,50ppm and 75ppm of different nano additives proportion are similar brake thermal efficiency up to $50 \%$ load conditions but it reached to $75 \%$ and $100 \%$ load conditions lesser efficiency compare with wpo20 blended fuel but, the $75 \mathrm{ppm}$ given the high brake thermal efficiency at the $75 \%$ and $100 \%$ load conditions which account of $5.72 \%$ increased compare with the wpo20 fuel.

\subsection{SPECIFIC FUEL CONSUMPTION}

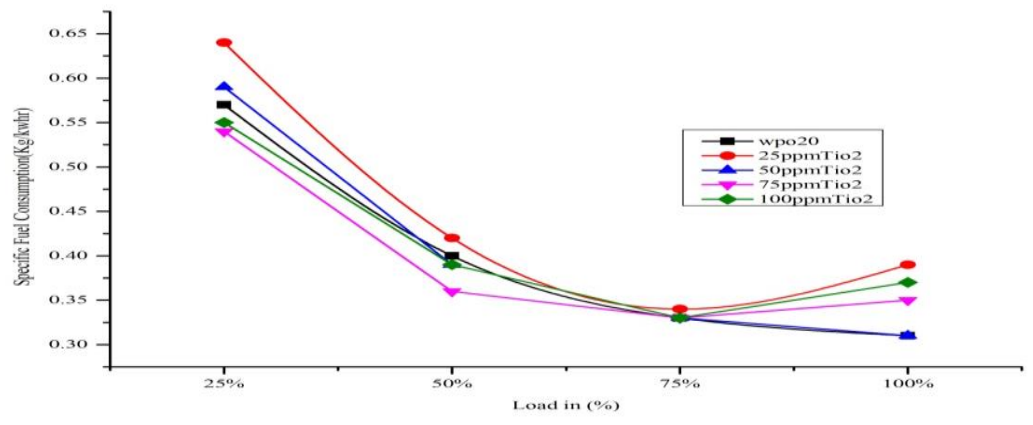

Fig.10. load vs specific fuel consumption

Figure.10 shows the specific fuel consumption figure shows the difference of the specific fuel consumptionforthedifferentnanoadditivesproportionlikewpo20,wpo20+25ppm,wpo20+50ppm,po20+75ppm and wpo20+100ppm with different load conditions in CRDi diesel engine. From the figures it is observed that the increasing the load conditions increase the brake specific fuel consumption also. At the wpo20+25ppm,wpo20+50ppm of different nano additives proportions blends are higher fuel consumption when compare with wpo20 fuel in all load conditions, but the wpo20+75ppm,wpo20+100ppm load conditions give less fuel consumption near $5.1 \%$ when compare with neat wpo20 fuel. 


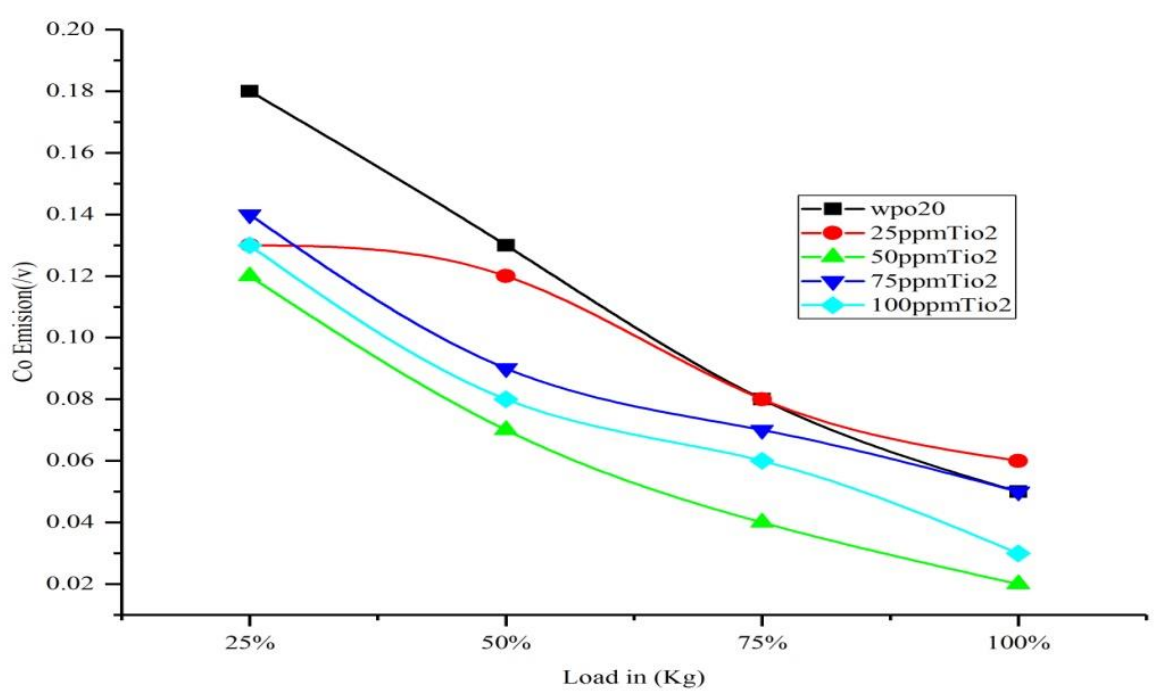

Fig.11. load vs co

Figure.10 shows the carbon monoxide emission figure shows the difference of the carbon monoxide for the different nano additives proportions like 25ppm, 50ppm, $75 \mathrm{ppm}$ and $100 \mathrm{ppm}$ with different load conditions in CRDi diesel engine. From the figures it is found that the increasing the load conditions diminish the carbon monoxide level simultaneously, the wpo20+25ppm,50ppm,75ppand 100ppm,all load conditions onwards gives low CO level when compare with neat wpo20 fuel. CO emissions are mainly formed by incomplete combustion and affected by the equivalence ratio and temperature. The wpo blending ratio results in higher $\mathrm{CO}$ emission because low cetane number of wpo and also lower in-cylinder peak pressure and incomplete oxidation at this condition.

\section{5}

\section{HC Emission}

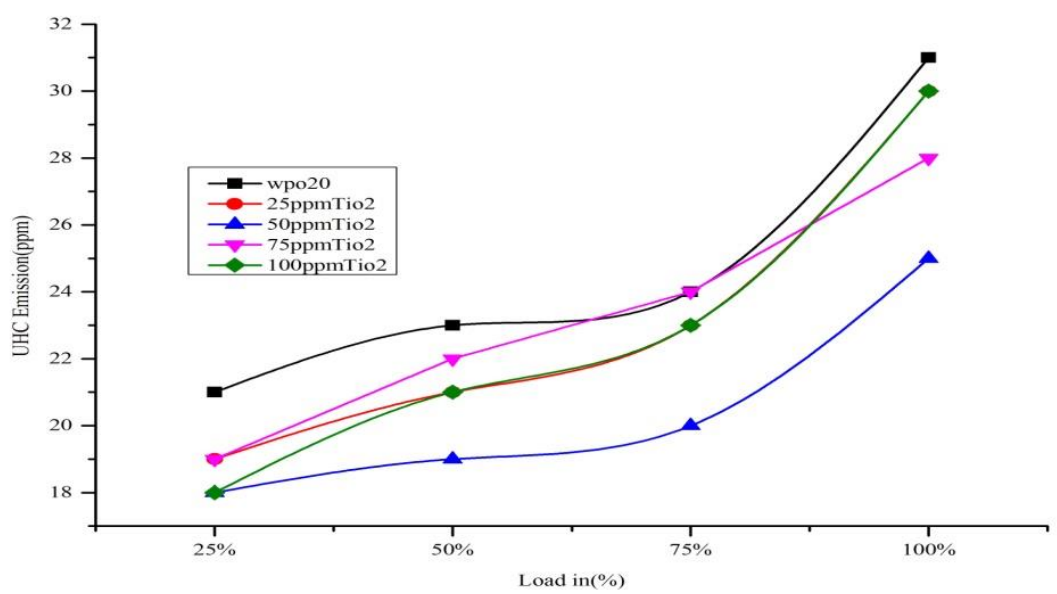

Fig.12. load vs unburned hydro carbons

Figure.12 shows the unburned hydro carbon emission figure shows the difference of the unburned hydro carbon emissions for the different nano additives proportions blends like wpo20,25ppm,50ppm,75ppmand 100ppm with different load conditions in CRDi diesel engine. From the figures it is noticed that the increasing the load conditions increase the unburned hydrocarbon level due to incomplete combustion simultaneously, the wpo20,25ppm, and 75ppm at all load conditions onwards gives high HC level when compare with neat wpo20 fuel. The reason that wpo blends 


\section{International Advanced Research Journal in Science, Engineering and Technology}

Vol. 8, Issue 8, August 2021

DOI: $10.17148 /$ IARJSET.2021.8827

results in higher UHC emission because the higher aromatics contents may be responsible ,another possible reason is the spray of wpo blends may have better chance to impinge the wall due to its higher density, lower viscosity and cetane number which result in longer ignition delay.

\section{NOx Emission.}

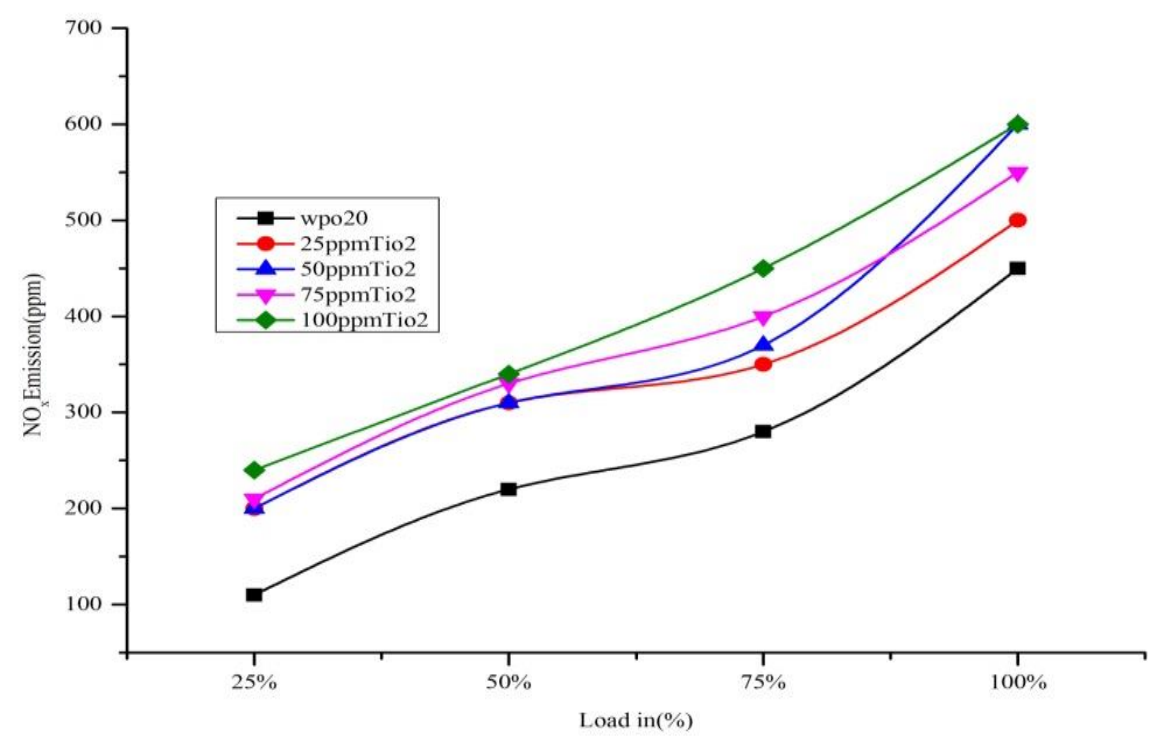

Fig.13. load vs oxides of nitrogen

The oxide of nitrogen figure shows the difference of the oxides of nitrogen for the different nano additives proportions fuel blends like wpo20,wpo20+25ppm,wpo20+50ppm,wpo20+75ppm and wpo100ppm with different load conditions in CRDi diesel engine. From the figure it is clear that the increasing the load conditions increase the oxides of nitrogen level simultaneously, the wpo 20+25ppm,50ppm,75ppmand 100ppm load conditions gives high NOx level when compare with neat wpo20 fuel. This is due to the longer ignition delay which results in higher portion of premixed combustion, thus higher heat release rate (HRR)and higher in-cylinder temperature another reason that may affect the NOx emission is the higher nitrogen content in the fuel that promotes the NOx formation by fuel mechanism

\section{Smoke opacity:}

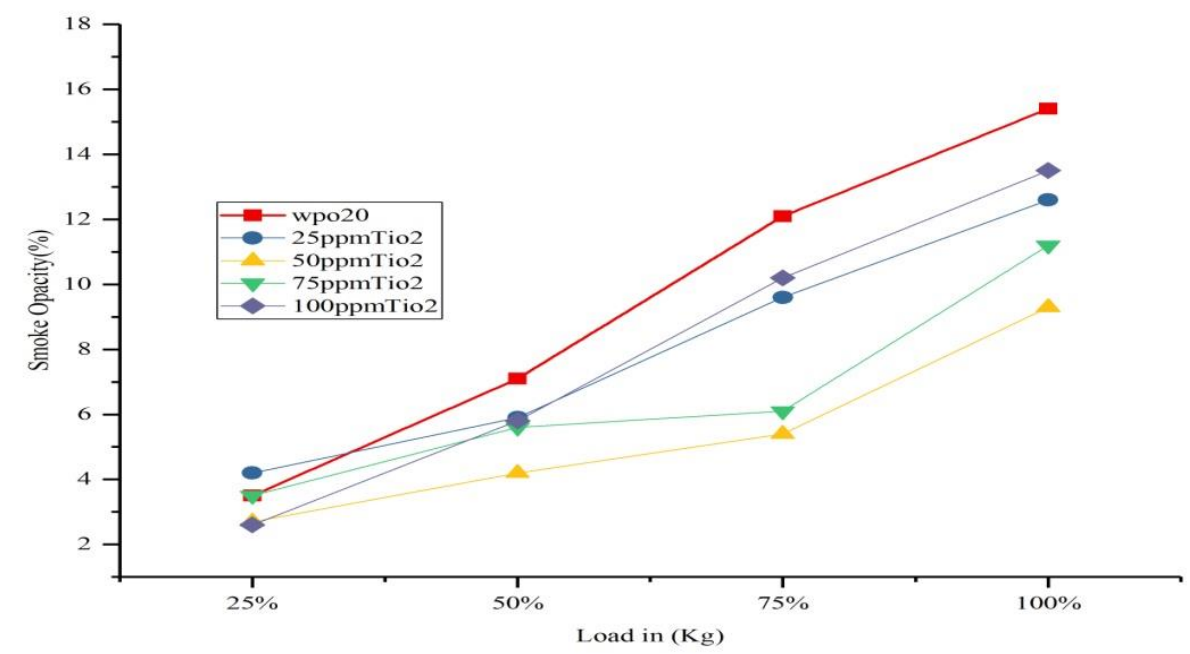

Fig.14. load vs Smoke opacity 


\title{
International Advanced Research Journal in Science, Engineering and Technology
}

\author{
Vol. 8, Issue 8, August 2021
}

\section{DOI: 10.17148/IARJSET.2021.8827}

The Smoke opacity figure shows the difference of the smoke opacity for the different nano additives proportions fuel blends like wpo20,wpo20+25ppm,wpo20+50ppm,wpo20+75ppm and wpo100ppm with different load conditions in CRDi diesel engine. From the figure it is clear that the increasing the load conditions increase the smoke opacity level simultaneously, the wpo 20,25ppm,75ppmand100 ppm at all load conditions gives high smoke opacity level when compare with wpo20+50ppm fuel. At the wpo20+50ppm blends are less smoke opacity level from initial stage to full load conditions when compare with neat diesel fuel.

\section{CONCLUSION}

The brake thermal efficiency of the wpo20, wpo20+25ppm, wpo20+50ppm, wpo20+75ppm and wpo100ppm of different blends are similar brake thermal efficiency up to $50 \%$ load conditions but it reached to $75 \%$ and $100 \%$ load conditions lesser efficiency compare with wpo20 fuel but, the wpo20+50ppm given the high brake thermal efficiency at the $75 \%$ and $100 \%$ load conditions which account of $5.72 \%$ increased compare with the wpo20 fuel.

The brake specific fuel consumption wpo20,wpo20+25ppm,wpo20+50ppm,wpo20+75ppm and wpo20+100ppm of different nano additives proportions are blends are higher fuel consumption when compare with wpo20 fuel in all load conditions, but the wpo20+75ppm,wpo20+100ppm load conditions give less fuel consumption near $5.1 \%$ when compare with neat wpo20 fuel.

The oxides of nitrogen level at the WPO20\%, blends are less oxides of nitrogen level from initial stage to full load conditions when compare with nano additives proportions. The carbon monoxide emission level is at the wpo20+50ppm blends are less carbon monoxide level from initial load to full load conditions when compare with neat wpo20 fuel.

The wpo20+25ppm,50ppm,75ppand 100ppm,all load conditions onwards gives low CO level when compare with neat wpo20 fuel. CO emissions are mainly formed by incomplete combustion and affected by the equivalence ratio and temperature. The wpo blending ratio results in higher $\mathrm{CO}$ emission because low cetane number of wpo and also lower in-cylinder peak pressure and incomplete oxidation at this condition.

The reason that wpo blends results in higher UHC emission because the higher aromatics contents may be responsible, another possible reason is the spray of wpo blends may have better chance to impinge the wall due to its higher density, lower viscosity and cetane number which result in longer ignition delay and adding the nano additives to plastic oil will give better performance and possible to reduce the emissions.

\section{REFERENCE}

1. Vigneswaran, R., Balasubramanian, D. and Sastha, B.S., Performance, emission and combustion characteristics of unmodified diesel engine with titanium dioxide (TiO2) nano particle along with water-in-diesel emulsion fuel. Fuel, 285 , p.119115.

2. Karthikeyan, S., Dharma Prabhakaran, T. and Prathima, A., 2018. Environment effect of La2O3 nano-additives on microalgae-biodiesel fueled CRDI engine with conventional diesel. Energy Sources, Part A: Recovery, Utilization, and Environmental Effects, 40(2), pp.179-185

3. Nanthagopal, K., Ashok, B., Tamilarasu, A., Johny, A. and Mohan, A., 2017. Influence on the effect of zinc oxide and titanium dioxide nanoparticles as an additive with Calophyllum inophyllum methyl ester in a CI engine. Energy Conversion and Management, 146, pp.8-19.

4. Praveen, A., Rao, G.L.N. and Balakrishna, B., 2018. Performance and emission characteristics of a diesel engine using Calophyllum inophyllum biodiesel blends with TiO2 nanoadditives and EGR. Egyptian journal of petroleum, 27(4), pp.731-738.

5. Basha, J.S. and Anand, R.B., 2010. Application of nanoparticle/nanofluid in compression ignition engines-A case study. International journal of applied engineering and research, pp.697-708.

6. Aalam, C.S., Saravanan, C.G. and Kannan, M., 2015. Experimental investigations on a CRDI system assisted diesel engine fuelled with aluminium oxide nanoparticles blended biodiesel. Alexandria Engineering Journal, 54(3), pp.351-358.

7. Devaraj, J., Robinson, Y. and Ganapathi, P., 2015. Experimental investigation of performance, emission and combustion characteristics of waste plastic pyrolysis oil blended with diethyl ether used as fuel for diesel engine. Energy, 85, pp.304-309.

8. $\quad$ Soudagar, M.E.M., Nik-Ghazali, N.N., Kalam, M.A., Badruddin, I.A., Banapurmath, N.R. and Akram, N., 2018. The effect of nanoadditives in diesel-biodiesel fuel blends: A comprehensive review on stability, engine performance and emission characteristics. Energy Conversion and Management, 178, pp.146-177

9. Ramesh Bapu, B.R., Senthil kumar, J., Shinde, Y.N. and Skaria, D.A., 2020. Emission investigation of VCR diesel engine by TiO2 nanocatalyst and Jamun biodiesel blended with diesel. International Journal of Ambient Energy, pp.1-8.

10. Aalam, C.S., 2020. Investigation on the combustion and emission characteristics of CRDI diesel engine fuelled with nano Al2O3 and Fe3O4 particles blended biodiesel. Materials Today: Proceedings, 33, pp.2540-2546.

11. D'Silva, R., Binu, K.G. and Bhat, T., 2015. Performance and Emission characteristics of a CI Engine fuelled with diesel and TiO2 nanoparticles as fuel additive. Materials Today: Proceedings, 2(4-5), pp.3728-3735.

12. Impact of various metal-oxide based nanoparticles and biodiesel blends on the combustion, performance, emission, vibration and noise characteristics of a CI engine

13. Selvaganapthy, A., Sundar, A., Kumaragurubaran, B. and Gopal, P., 2013. An experimental investigation to study the effects of various nano particles with diesel on DI diesel engine. ARPN Journal of Science and Technology, 3(1), pp.112-115.

14. Krishna Chaitanya, A.V.R. and Pappula, B., 2017. Impact of Waste Plastic Oil and Its Blends on Performance Combustion and Emission Characteristics of CRDI Engine (No. 2019-28-0047).

15. Ayodhya, A.S., Lamani, V.T., Bedar, P. and Kumar, G.N., 2018. Effect of exhaust gas recirculation on a CRDI engine fueled with waste plastic oil blend. Fuel, 227, pp.394-400

16. Panithasan, M.S., 2020. Exploring the Preparation and Usage of Low Viscous Pine Oil and Rice Husk Nano Additives in a CRDI Engine under the Effect of Water Emulsion (No. 2020-01-2128). SAE Technical Paper.

17. Pradeep, P. and Senthilkumar, M., 2019. Simultaneous reduction of emissions as well as fuel consumption in CI engine using water and nanoparticles in Diesel-Biodiesel blend. Energy Sources, Part A: Recovery, Utilization, and Environmental Effects, pp.1-11. 


\section{International Advanced Research Journal in Science, Engineering and Technology}

Vol. 8, Issue 8, August 2021

\section{DOI: 10.17148/IARJSET.2021.8827}

18. Rupa Athimakula; Lakshmi Kanth; Sai BargavChowdary B; Ismail Kakarwada. "Modeling and Analysis of Cylinder Block for V8 Engine". International Research Journal on Advanced Science Hub, 2, 12, 2020, 30-40. doi: 10.47392/irjash.2020.245

19. Karthick U; Venkatajalapathi T; VimalKodeeswaran A; Ashok Kumar P. "Performance and emission analysis in four stroke diesel engine using biodiesel blends as fuel". International Research Journal on Advanced Science Hub, 1, 1, 2019, 50-56. doi: 10.47392/irjash.2019.08

20. Ramalingam, K., Kandasamy, A., Subramani, L., Balasubramanian, D. and Thadhani, J.P.J., 2018. An assessment of combustion, performance characteristics and emission control strategy by adding anti-oxidant additive in emulsified fuel. Atmospheric Pollution Research, 9(5), pp.959-967.

21. Prabakaran, B., 2020. Influence of Butanol and Nano Titanium Oxide into Non Edible Cotton Seed Oil Biodiesel on the Performance of CI Engine (No. 2020-01-2134). SAE Technical Paper. 